\title{
Preliminary marker-based validation of a novel biplane fluoroscopy system
}

\author{
Joseph M laquinto ${ }^{1}$, Richard Tsai', Michael Fassbind ${ }^{1}$, David R Haynor ${ }^{2}$, Bruce J Sangeorzan ${ }^{1,3}$, \\ William R Ledoux ${ }^{1,3,4^{*}}$
}

From 3rd Congress of the International Foot and Ankle Biomechanics Community

Sydney, Australia. 11-13 April 2012

\section{Background}

The use of biplane fluoroscopy to track bones in the foot is challenging, due to distortion, overlap and image artefact inherent in fluoroscopy systems and high speed photography. The accuracy and precision of these systems have been reported [1-4] and are presented here for our biplane fluoroscopy system.

\section{Materials and methods}

Biplane Fluoroscopy System: The system consists of two Philips BV Pulsera C-arms set in custom frames around a raised floor with a radiolucent imaging area. X-ray images are captured with high speed (1000fps) cameras.
Validation Object: $1.6 \mathrm{~mm}$ tantalum beads were placed in a machined block (wand) then measured to 7 microns with a Coordinate Measuring Machine to determine their centroid location. The wand was translated and rotated via a 1 micron precision stepper-motor for static validation, as well as manually swept through the field of view at $\sim 0.5 \mathrm{~m} / \mathrm{s}$ for dynamic. Static Accuracy and Precision: accuracy was defined as the RMS error between the translation of the stepper-motor and the measured movement of the beads; precision is defined as the standard deviation of the bead locations. For rotation, accuracy was defined as the RMS error between the applied and measured rotation of the wand.

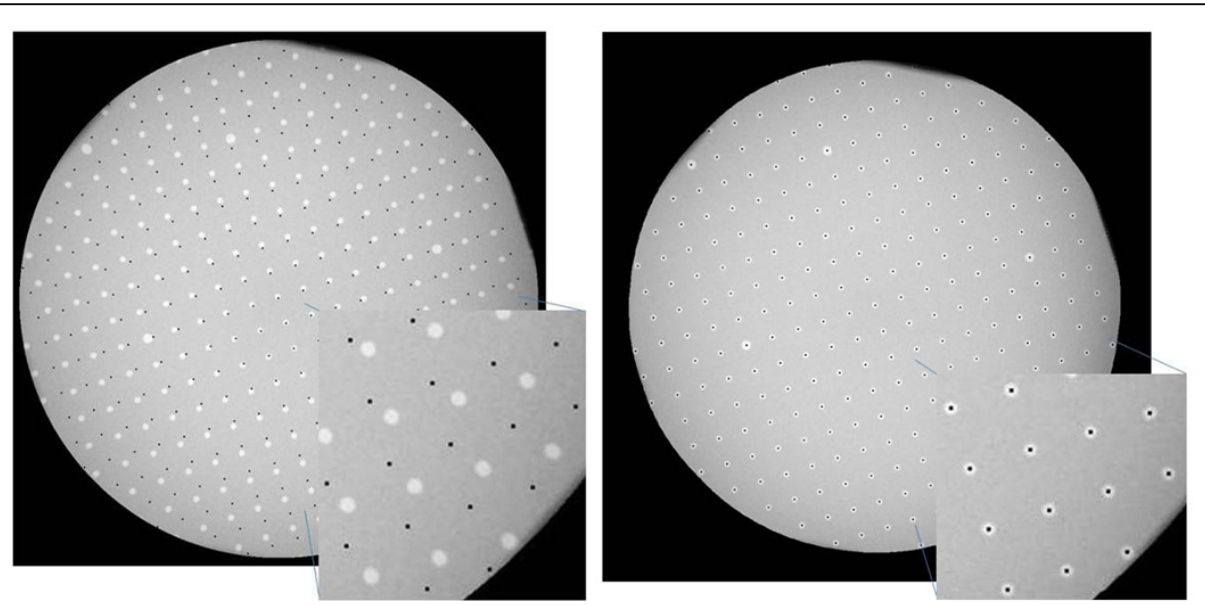

Figure 1 Distortion plate before (left) and after (right) correction for pin-hole distortion and magnetic distortion.

\footnotetext{
* Correspondence: wrledoux@u.washington.edu

'VA RR\&D Center of Excellence for Limb Loss Prevention and Prosthetic

Engineering, Seattle, WA, 98108, USA

Full list of author information is available at the end of the article
}

(c) 2012 laquinto et al; licensee BioMed Central Ltd. This is an Open Access article distributed under the terms of the Creative Commons :-1 Med Central Attribution License (http://creativecommons.org/licenses/by/2.0), which permits unrestricted use, distribution, and reproduction in any medium, provided the original work is properly cited. 
Dynamic Accuracy and Precision: accuracy was defined as the RMS error between the known and measured inter-bead distance; precision was the standard deviation of the inter-bead distance. 3D location processing was accomplished using custom software written in MatLab to derive the 3D location of objects from two, time-synchronized, 2D fluoroscopy images of known spatial relationship. This software also compensates for the image distortion (Figure 1).

\section{Results}

Translation: the overall RMS error was $0.066 \mathrm{~mm}$, with a precision of $\pm 0.016 \mathrm{~mm}$. Rotation: the RMS error was $0.125^{\circ}$. Dynamic motion: the overall RMS error was $0.126 \mathrm{~mm}$, with a precision of $\pm 0.122 \mathrm{~mm}$.

\section{Conclusions}

The accuracies and precision in the results are comparable to similar such systems in development to investigate other joints of the body [1-4]. We are currently developing and validating a marker-less technique for tracking the bones of the foot.

\section{Author details}

'VA RR\&D Center of Excellence for Limb Loss Prevention and Prosthetic Engineering, Seattle, WA, 98108, USA. ${ }^{2}$ Departments of Radiology and Bioengineering, University of Washington, Seattle, WA, 98195-7117, USA. ${ }^{3}$ Department of Orthopaedics \& Sports Medicine, University of Washington, Seattle, WA, 98195-6500, USA. ${ }^{4}$ Department of Mechanical Engineering,

University of Washington, Seattle, WA, 98195, USA.

Published: 10 April 2012

\section{References}

1. Brainerd EL, et al: X-ray reconstruction of moving morphology (XROMM): precision, accuracy and applications in comparative biomechanics research. J Exp Zool A Ecol Genet Physiol 2010, 313:262-279.

2. Miranda $D$, et al: Accuracy and precision of 3-D skeletal motion capture technology. 56th ORS 2010, Paper no. 334.

3. $L i \mathrm{G}$, et al: Validation of a non-invasive fluoroscopic imaging technique for the measurement of dynamic knee joint motion. J Biomech 2008, 41:1616-1622.

4. Kaptein BL, et al: A comparison of calibration methods for stereo fluoroscopic imaging systems. J Biomech 2011, 44:2511-2515.

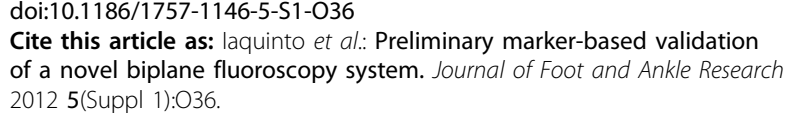

\section{Submit your next manuscript to BioMed Central} and take full advantage of:

- Convenient online submission

- Thorough peer review

- No space constraints or color figure charges

- Immediate publication on acceptance

- Inclusion in PubMed, CAS, Scopus and Google Scholar

- Research which is freely available for redistribution

Submit your manuscript at www.biomedcentral.com/submit
C Biomed Central 